\title{
Arterial stiffness, ambulatory blood pressure and low-grade albuminuria in non-diabetic African and Caucasian men: the SABPA study
}

\author{
Rudolph Schutte, Aletta E Schutte, Hugo W Huisman, Matthew CP Glyn, Johannes M van Rooyen, \\ Nicolaas T Malan, Carla MT Fourie and Leoné Malan
}

Recent evidence suggests that low-grade urinary albumin excretion is a marker of early general attenuation of vascular function, but studies are limited to Caucasian population groups. We compared low-grade urinary albumin excretion $\left(<3.5 \mathrm{mg} \mathrm{mmol}^{-1}\right.$ or $30 \mu \mathrm{g} \mathrm{mg}^{-1}$ ) between non-diabetic African (aged, 41.7 years; $n=70$ ) and Caucasian (aged, 44.6 years; $n=91$ ) men and ethnic-specific associations thereof with arterial stiffness and ambulatory blood pressure. The albumin-to-creatinine ratio (ACR) was determined from an $8 \mathrm{~h}$ overnight urine collection. We recorded ambulatory blood pressure over $24 \mathrm{~h}$ during a typical workday and the carotid-dorsalis pedis pulse wave velocity measured the next morning after a controlled overnight stay. ACR was higher in Africans compared with Caucasians $(P<0.001)$, also after adjusting for $24 \mathrm{~h}$ systolic blood pressure, diastolic blood pressure and hypertension prevalence $(P<0.001)$ or when grouped by similar $24 \mathrm{~h}$ mean arterial pressures $(P<0.01$ for all categories). Daytime $(P=0.002)$ and night time $(P<0.001)$ systolic and daytime $(P<0.001)$ and night time $(P<0.001)$ diastolic blood pressures were higher in Africans compared with Caucasians, but no differences existed for daytime and night time pulse pressure and pulse wave velocity. In African men only, after adjustment for covariates, night time systolic blood pressure $(\beta=0.347 ; P=0.003)$, diastolic blood pressure $(\beta=0.298 ; P=0.010)$ and mean arterial pressure $(\beta=0.331 ; P=0.004)$ correlated positively with ACR. In addition, daytime $(\beta=0.265 ; P=0.032)$ and night time $(\beta=0.258 ; P=0.038)$ pulse pressure as well as pulse wave velocity $(\beta=0.271 ; P=0.032)$ correlated positively with ACR. In conclusion, arterial stiffness and ambulatory blood pressure are already associated with low-grade albuminuria in non-diabetic African men with normal kidney function.

Hypertension Research (2011) 34, 862-868; doi:10.1038/hr.2011.45; published online 28 April 2011

Keywords: albuminuria; ambulatory blood pressure; arterial stiffness; ethnicity

\section{INTRODUCTION}

The average life expectancy for people living in sub-Saharan Africa is 46 years compared with that of 78 years for the United States and 80 years for the United Kingdom. ${ }^{1}$ The current prominence of HIV infection and other infectious diseases such as tuberculosis and malaria in Africans contribute most significantly to this disturbing statistic.,3 However, predictions are made that cardiovascular disease will soon eclipse infectious diseases as the leading cause of death and disability in sub-Saharan Africa. ${ }^{4,5}$ Indeed, high rates of hypertension ${ }^{6}$ and peripheral arterial disease ${ }^{7}$ observed in Africans behave in an explosive and debilitating manner, with death occurring frequently from stroke, ${ }^{8}$ renal failure $^{9}$ or congestive heart failure. ${ }^{10}$ To combat this trend, the early identification of high-risk subjects with subtle abnormalities in vascular function is important to curb the progression to cardiovascular disease through preventative treatment strategies.
Microalbuminuria, defined as an albumin-to-creatinine ratio (ACR) above $3.5-30 \mathrm{mg} \mathrm{mmol}^{-1}$ (or $30 \leqslant 300 \mu \mathrm{g} \mathrm{mg}^{-1}$ ), ${ }^{11}$ is an established risk factor for cardiovascular morbidity and mortality and for end-stage renal disease, especially in individuals with hypertension and diabetes mellitus. ${ }^{12-14}$ It is regarded not only as a marker of glomerular endothelial damage, but also reflects general endothelial damage $^{15-18}$ and related arterial stiffness. ${ }^{19}$ There is a growing body of evidence showing that low-grade albuminuria, well below $3.5 \mathrm{mg} \mathrm{mmol}^{-1}$, is associated with blood pressure increase, ${ }^{20,21}$ endothelial dysfunction, ${ }^{22,23}$ arterial stiffness ${ }^{24}$ and the development of cardiovascular disease ${ }^{25}$ in healthy non-diabetic individuals without chronic kidney disease. Unfortunately, the above evidence is predominantly from Caucasian population groups. If it holds true for non-diabetic sub-Saharan Africans with normal kidney function, then low-grade albuminuria could perhaps be used as a low-cost

Hypertension in Africa Research Team (HART), School for Physiology, Nutrition, and Consumer Sciences, North-West University (Potchefstroom Campus), Potchefstroom, South Africa

Correspondence: Dr R Schutte, Hypertension in Africa Research Team (HART), School for Physiology, Nutrition, and Consumer Sciences, Private Bag x6001, North-West University (Potchefstroom Campus), Potchefstroom 2520, South Africa.

E-mail: rudolph.schutte@nwu.ac.za

Received 23 November 2010; revised 26 January 2011; accepted 13 February 2011; published online 28 April 2011 
marker of subtle vascular/endothelial damage and therefore initiate early treatment to help curb the increasing trend of cardiovascularrelated morbidity and mortality in this population group.

The aims of this study were first to compare albumin excretion between non-diabetic African and Caucasian men with normal kidney function and second to investigate ethnic-specific associations between arterial stiffness, ambulatory blood pressure and low-grade albuminuria.

\section{METHODS}

\section{Study population}

This study is embedded in the SABPA (Sympathetic Activity and Ambulatory Blood Pressure in Africans) study conducted in 2008 and 2009. We recruited 202 urbanized African $(n=101)$ and Caucasian $(n=101)$ male educators working in the Dr Kenneth Kaunda district in the North West Province, South Africa. The reason for this selection was to obtain a homogeneous sample from a similar socio-economic class. We invited all eligible participants between the ages of 25 and 65 years to participate. Exclusion criteria were an elevated ear temperature, psychotropic substance dependence or abuse, regular blood donors and individuals vaccinated in the past 3 months. We excluded 31 African men (ACR $>3.5 \mathrm{mg} \mathrm{mmol}^{-1}, 11 \quad n=10$; impaired fasting glucose, $>7 \mathrm{mmoll}^{-1}, 26 \quad n=10$; HIV infected, $n=11$ ) and 10 Caucasian men (ACR $>3.5 \mathrm{mg} \mathrm{mmol}^{-1}, n=1$; impaired fasting glucose, $>7 \mathrm{mmoll}^{-1}, n=9$; HIV infected, $n=0)$.

Participants were fully informed about the objectives and procedures of the study before their inclusion. Assistance was available for any participant who requested conveyance of information in their home language. All participants signed an informed consent form. The study complied with all applicable requirements of international regulations, in particular the Declaration of Helsinki of 1975 (as revised in 2004) for investigation of human participants. The Ethics Review Board of the North-West University (Potchefstroom Campus) approved the study.

\section{Cardiovascular measurements}

We conducted $24 \mathrm{~h}$ ambulatory blood pressure measurements (ABPM) during workdays. At approximately 0800 hours, an ABPM apparatus (Meditech CE120 Cardiotens; Meditech, Budapest, Hungary) was attached to the participants' nondominant arm at their workplace. The ABPM apparatus was programmed to measure blood pressure at 30-min intervals during the day (0800-2200 hours) and every hour during night time (2200-0600 hours). Participants continued with their normal daily activities and recorded any abnormalities such as headache, nausea and stress on their ambulatory diary cards.

Participants were admitted at 1630 hours to the Metabolic Unit Research Facility of the North-West University. This facility consists of 10 bedrooms, two bathrooms, a living room and kitchen. They received a standardized dinner and had their last beverages (tea/coffee) and two biscuits at 2030 hours. Thereafter, they relaxed by reading, watching television, or social interaction and refrained from consuming alcohol, caffeine, smoking and doing exercise. They were requested to go to bed at around 2200 hours. At 0600 hours, the ABPM apparatus was removed and subsequent measurements commenced. We downloaded the $24 \mathrm{~h}$ blood pressure and electrocardiogram data onto a database using the CardioVisions 1.9.0 Personal Edition (Meditech). The successful inflation rate over the $24 \mathrm{~h}$ period was $74.9 \pm 9.3 \%$ for the Africans and $84.3 \pm 9.3 \%$ for the Caucasians. Hypertension was defined as a mean $24 \mathrm{~h}$ systolic blood pressure of at least $130 \mathrm{~mm} \mathrm{Hg}$ or diastolic blood pressure of at least $80 \mathrm{~mm} \mathrm{Hg} .{ }^{27}$ Pulse pressure was the difference between $24 \mathrm{~h}$ systolic and diastolic blood pressure and was used as an indirect measure of aortic stiffness. ${ }^{28}$ In addition to ambulatory blood pressure, and after at least $5 \mathrm{~min}$ rest, duplicate blood pressure readings were taken $5 \mathrm{~min}$ apart by making use of a single-headed stethoscope and a table model mercury sphygmomanometer.

Pulse wave velocity was determined non-invasively from an arterial segment that includes both elastic and muscular arteries by measuring the superficial pulses at the carotid and dorsalis pedis arteries using the Complior SP device (Artech-Medical, Pantin, France). All measurements were taken by the same two observers for all participants. The pulse wave velocity was measured on the left side of each participant while lying in the supine position.

\section{Anthropometric and physical activity measurements}

Height (stature) and weight of participants in their underwear were measured using calibrated instruments (Precision Health Scale, A \& D Company, Tokyo, Japan; Invicta Stadiometer, IP 1465, UK). Measurements were taken in triplicate using standard methods. ${ }^{29}$ To assess physical activity, participants wore Actical accelerometers (Montréal, Québec, Canada) around their hip during a normal working day. The Actical is an omnidirectional accelerometer (that is, is sensitive to movements in all planes), and has been validated during treadmill walking, running and lifestyle activities performed in a laboratory. ${ }^{30}$

\section{Biochemical measurements}

After completion of the anthropometric measurements, a registered nurse obtained a blood sample with a sterile winged infusion set from the antebrachial vein branches. Urine was collected overnight for a period of $8 \mathrm{~h}$. Serum and urine were stored at $-80^{\circ} \mathrm{C}$.

In serum, fasting samples for total cholesterol, HDL cholesterol, highsensitivity C-reactive protein and creatinine were analyzed using the sequential multiple analyzer computer (Konelab 20i TM, Thermo Scientific, Vantaa, Finland). Glucose was determined using a timed end point method (Unicel DXC 800; Beckman and Coulter, Krefeld, Germany).

In urine, creatinine was determined with a calorimetric method and albumin with the measurement of immunoprecipitation enhanced by polyethylene glycol at $450 \mathrm{~nm}$ with sequential multiple analyzer computer (Konelab 20i TM, Thermo Scientific, Vantaa, Finland) with a coefficient of variation of $1.7-3.3 \%$. ACR measured in spot urine samples or over $8 \mathrm{~h}$ is highly correlated with $24 \mathrm{~h}$ urine albumin excretion. ${ }^{31-33}$ We calculated the estimated creatinine clearance by using the Cockcroft-Gault formula. ${ }^{34}$

All biochemical measurements were performed by an independent laboratory, blinded to the subjects' cardiovascular profile.

\section{Statistical analyses}

For database management and statistical analyses, we used SAS software version 9.1 (SAS Institute Inc., Cary, NC, USA). The distribution of urinary creatinine, urinary albumin, ACR, high-sensitivity C-reactive protein, serum glucose and physical activity were normalized by logarithmic transformation. The central tendency and spread of these variables were represented by the geometric mean and the 5th and 95th percentile intervals. We compared means and proportions by a standard $t$-test and the $\chi^{2}$ test, respectively. Mean values of ambulatory blood pressure, pulse pressure and pulse wave velocity were plotted by quartiles of ACR to ensure that linear correlation techniques were appropriate. We investigated associations between these cardiovascular variables and ACR using single and multiple linear regressions. Covariates entered in the model were age, body mass index, serum glucose, C-reactive protein, physical activity, current smoking, current drinking and use of antihypertensive medication. All $P$-values refer to two-sided hypotheses.

\section{RESULTS}

\section{Characteristics of participants}

Table 1 lists the African and Caucasian men's characteristics. The Africans $(n=70)$ tended to be younger $(P=0.059)$ with lower serum glucose $(P<0.001)$ and total cholesterol $(P<0.001)$ levels compared with the Caucasians $(n=91)$. On the other hand, the Africans smoked more $(P=0.040)$, were physically less active $(P<0.001)$ and had higher C-reactive protein levels $(P=0.026)$. The ACR $(P<0.001)$, daytime systolic $(P=0.002)$, diastolic $(P<0.001)$ and mean arterial pressure $(P<0.001)$, as well as the night time systolic $(P<0.001)$, diastolic $(P<0.001)$ and mean arterial pressure $(P<0.001)$ were higher in African compared with Caucasian men.

Seventy percent of the Africans and $52 \%$ of the Caucasians were hypertensive $(P=0.027)$.

Owing to the higher blood pressure and hypertension prevalence in the Africans, we adjusted for $24 \mathrm{~h}$ systolic and diastolic blood pressure and hypertension prevalence to see if urinary albumin excretion would still be higher in the African group. By doing so, the ACR did indeed 
Table 1 Characteristics of African and Caucasian men

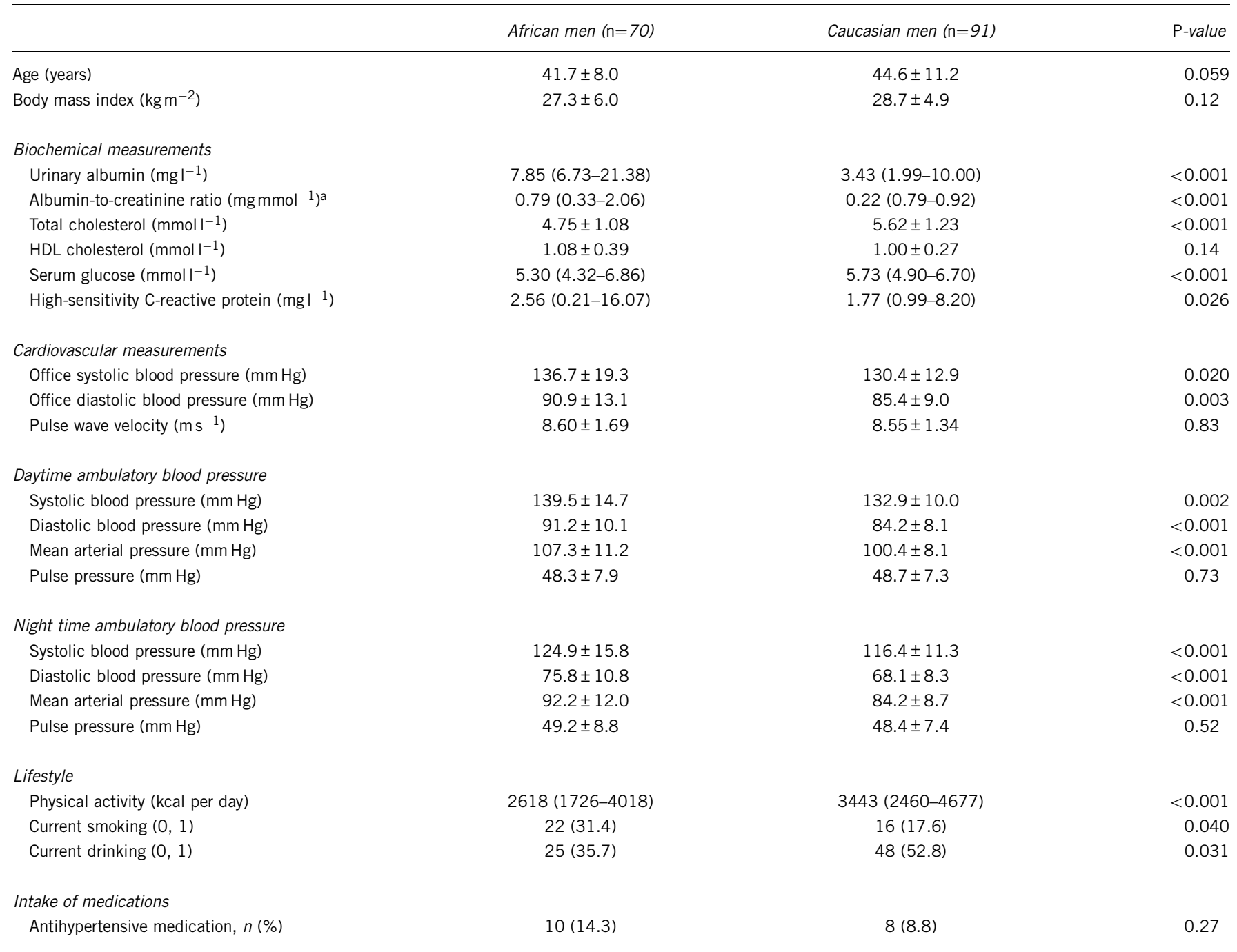

Abbreviation: HDL, high-density lipoprotein.

Values are arithmetic mean \pm s.d., geometric mean (5th to 95 th percentile interval) or number of subjects (\%).

aTo convert from $\mathrm{mg} \mathrm{mmol}^{-1}$ to $\mu \mathrm{g} \mathrm{mg}^{-1}$, divide by 0.112 .

remain higher in the Africans ( 0.77 vs. $\left.0.23 \mathrm{mg} \mathrm{mmol}^{-1}, P<0.001\right)$. In addition, we stratified the groups by $24 \mathrm{~h}$ mean arterial pressure and adjusted for age and body mass index to compare ACR between the ethnic groups at similar blood pressures (Figure 1). Again, ACR was higher $(P<0.01)$ in Africans at each category of $24 \mathrm{~h}$ mean arterial pressure, confirming that this ethnic difference is independent of blood pressure. Lastly, kidney function was well within normal limits in the Africans (that is, serum creatinine, $77.2 \pm 13.9 \mu \mathrm{moll}^{-1}$; estimated creatinine clearance, $127.7 \pm 34.1 \mathrm{ml} \mathrm{min}^{-1}$; and ACR, 0.79 $\left(0.33-2.06 \mathrm{mg} \mathrm{mmol}^{-1}\right)$. Unfortunately, these measures of kidney function were unavailable for the Caucasians.

\section{Unadjusted analysis}

In African men only (Table 2), we noticed significant positive associations of night time systolic blood pressure and mean arterial pressure with ACR, whereas night time diastolic blood pressure and pulse pressure, as well as pulse wave velocity tended to increase with increasing albumin excretion. No associations were obtained between daytime blood pressure and ACR.

\section{Adjusted analysis}

In exploratory analyses (Table 3), we investigated the cardiovascular variables of the African men across quartiles of ACR, while adjusting for age and body mass index. Again, night time systolic blood pressure $(P$ for trend, 0.025$)$ and mean arterial pressure $(P$ for trend, 0.045$)$ increased significantly, whereas night time diastolic blood pressure ( $P$ for difference between the lowest and highest quartile, 0.022) and pulse pressure ( $P$ for difference between the lowest and highest quartile, 0.067) tended to increase with increasing ACR. Of note is that daytime pulse pressure also tended to increase with increasing ACR ( $P$ for difference between the lowest and highest quartile, 0.083)

The independent associations between the cardiovascular variables and ACR in African and Caucasian men are shown in Table 4. With adjustments applied for covariates (age, body mass index, serum glucose, high-sensitivity C-reactive protein, physical activity, current smoking, current drinking and use of antihypertensive medication), the above associations were not only confirmed, but the borderline significant associations became significant. In African men, night time systolic blood pressure $(P=0.003)$, diastolic blood pressure $(P=0.010)$, 

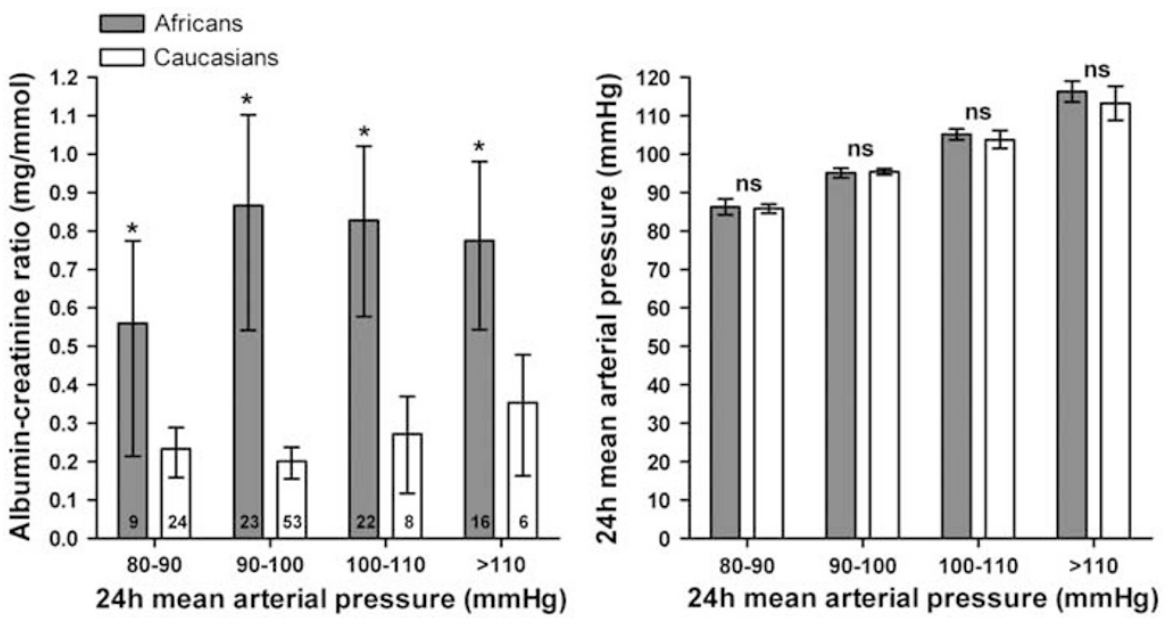

Figure 1 Albumin-to-creatinine ratio and $24 \mathrm{~h}$ mean arterial pressure by ethnicity and category of $24 \mathrm{~h}$ mean arterial pressure adjusted for age and body mass index. Charted values are means and bars represent $95 \%$ confidence limits. ${ }^{*} P$-value less than 0.01 and NS, nonsignificant for differences between African and Caucasian men.

Table 2 Associations between ambulatory blood pressure and albumin-to-creatinine ratio in single regression analyses

\begin{tabular}{lcc}
\hline & \multicolumn{2}{c}{ Albumin-to-creatinine ratio } \\
\cline { 2 - 3 } & \multicolumn{1}{c}{ African men } & Caucasian men \\
\hline Daytime & & \\
Systolic blood pressure & $r=0.06 ; P=0.59$ & $r=0.10 ; P=0.36$ \\
Diastolic blood pressure & $r=-0.05 ; P=0.71$ & $r=0.16 ; P=0.12$ \\
Mean arterial pressure & $r=0.001 ; P=0.99$ & $r=0.15 ; P=0.16$ \\
& & \\
Night time & & $r=0.02 ; P=0.83$ \\
Systolic blood pressure & $r=0.26 ; P=0.032$ & $r=0.03 ; P=0.79$ \\
Diastolic blood pressure & $r=0.21 ; P=0.081$ & $r=0.027 ; P=0.80$ \\
Mean arterial pressure & $r=0.24 ; P=0.047$ & \\
Arterial stiffness & & $r=-0.09 ; P=0.38$ \\
$\begin{array}{l}\text { Pulse wave velocity } \\
\text { Daytime pulse pressure } \\
\text { Night time pulse pressure }\end{array}$ & $r=0.23 ; P=0.062$ & $r=-0.05 ; P=0.67$ \\
\hline
\end{tabular}

mean arterial pressure $(P=0.004)$ and pulse pressure $(P=0.038)$ correlated positively with ACR, whereas the associations of daytime pulse pressure $(P=0.032)$ and pulse wave velocity $(P=0.032)$ with ACR became significant. All the associations obtained above were absent in Caucasian men.

\section{Sensitivity analysis}

As indicated previously, kidney function was within normal limits in the African group. However, to ensure that the associations obtained were truly independent of renal function, we additionally adjusted for estimated creatinine clearance. By doing so, the associations of night time systolic blood pressure $\left(R^{2}=0.326, \beta=0.344, P=0.004\right)$, diastolic blood pressure $\left(R^{2}=0.331, \beta=0.295, P=0.011\right)$ and mean arterial pressure $\left(R^{2}=0.343, \beta=0.328, P=0.005\right)$, as well as night time pulse pressure $\left(R^{2}=0.208, \beta=0.257, P=0.041\right)$, daytime pulse pressure $\left(R^{2}=0.229, \beta=0.271, P=0.029\right)$ and pulse wave velocity $\left(R^{2}=0.327\right.$, $\beta=0.278, P=0.029$ ) with ACR remained significant.

\section{DISCUSSION}

This study investigated low-grade albumin excretion in normoglycemic African and Caucasian men with normal kidney function and its possible role as marker of general vascular dysfunction. Although blood pressure was higher in African men, albumin excretion was higher in the Africans independent of blood pressure. In addition, measures of arterial stiffness and night time blood pressure were independently associated with urinary albumin excretion in African men, but not in Caucasian men. These associations were also independent of kidney function.

Our findings support previous prospective studies that included only Caucasian population groups. These studies showed that microalbuminuria $\left(>3.5 \mathrm{mg} \mathrm{mmol}^{-1}\right.$ ) and macroalbuminuria $\left(>30 \mathrm{mg} \mathrm{mmol}^{-1}\right.$ ) were associated with a higher risk of cardiovascular disease incidence and mortality in patients with hypertension ${ }^{12,35}$ or diabetes. ${ }^{36}$ Recently, Ärnlöv et al. ${ }^{25}$ reported that even low-grade urinary albumin excretion (mean ACR $1.21 \mathrm{mg} \mathrm{mmol}^{-1}$ ) is associated with increased risk of cardiovascular disease and mortality in non-hypertensive, non-diabetic individuals and individuals with a low to intermediate pre-test probability of vascular events. They therefore supported the hypothesis that low-grade albuminuria in apparently healthy individuals may also be a marker of extra-renal subclinical vascular damage or dysfunction that predisposes to future cardiovascular disease and death. ${ }^{25}$ This is also supported by our associations obtained in African men with a mean ACR of $0.79 \mathrm{mg} \mathrm{mmol}^{-1}$, well below the diagnostic threshold for microalbuminuria. ${ }^{11}$

However, the presence of albumin in the urine as a marker of vascular damage could also merely be confined to glomerular endothelial damage due to exposure to chronically elevated blood pressure, ${ }^{37,38}$ and therefore serve as an explanation for the associations obtained between night time blood pressure and low-grade albuminuria in our study. This is especially true for salt-sensitive individuals, such as Africans, ${ }^{39}$ and individuals with diabetic nephropathy, ${ }^{40}$ where elevated blood pressure is required to excrete a sodium load, especially during the night and therefore believed to contribute to nondipping. ${ }^{41}$ Over time, chronically elevated blood pressure leads to glomerular scarring and endothelial dysfunction, ${ }^{38,42}$ causing leaking of albumin into the renal tubules.

On balance, Wang et al. ${ }^{21}$ and others ${ }^{20}$ found that low-grade albumin excretion does, in fact, predict blood pressure progression 
Table 3 Ambulatory blood pressure of African men across quartiles of albumin-to-creatinine ratio

\begin{tabular}{|c|c|c|c|c|c|c|}
\hline \multirow[b]{2}{*}{ Characteristics } & \multicolumn{4}{|c|}{ Quartiles of the distribution of albumin-to-creatinine ratio } & \multicolumn{2}{|c|}{ P-values } \\
\hline & Low & Medium-low & Medium-high & High & For trend & For low vs. high \\
\hline Means (mg mmol ${ }^{-1}$ ) & $0.39(0.17-0.58)$ & $0.71(0.59-0.84)$ & $0.96(0.85-1.09)$ & $1.53(1.10-3.22)$ & & \\
\hline Number & 18 & 17 & 18 & 17 & & \\
\hline Age (years) & $41.7 \pm 8.4$ & $40.4 \pm 7.6$ & $43.9 \pm 6.1$ & $40.7 \pm 9.8$ & 0.56 & 0.72 \\
\hline Systolic blood pressure $(\mathrm{mm} \mathrm{Hg})$ & $138.4 \pm 13.1$ & $140.1 \pm 13.2$ & $136.2 \pm 13.3$ & $143.5 \pm 13.2$ & 0.44 & 0.26 \\
\hline Diastolic blood pressure $(\mathrm{mm} \mathrm{Hg})$ & $91.4 \pm 9.3$ & $91.9 \pm 9.4$ & $89.5 \pm 9.4$ & $92.0 \pm 9.3$ & 0.86 & 0.86 \\
\hline Mean arterial pressure $(\mathrm{mm} \mathrm{Hg})$ & $107.1 \pm 10.1$ & $108.0 \pm 10.2$ & $105.1 \pm 10.3$ & $109.2 \pm 10.2$ & 0.70 & 0.55 \\
\hline \multicolumn{7}{|l|}{ Night time } \\
\hline Systolic blood pressure $(\mathrm{mm} \mathrm{Hg})$ & $120.1 \pm 13.8$ & $126.5 \pm 13.9$ & $120.6 \pm 13.9$ & $133.1 \pm 13.8$ & 0.025 & 0.007 \\
\hline Pulse wave velocity $\left(\mathrm{m} \mathrm{s}^{-1}\right)$ & $8.6 \pm 1.6$ & $7.9 \pm 1.5$ & $9.0 \pm 1.6$ & $8.9 \pm 1.5$ & 0.14 & 0.47 \\
\hline Daytime pulse pressure $(\mathrm{mm} \mathrm{Hg})$ & $47.0 \pm 7.5$ & $48.2 \pm 7.5$ & $46.7 \pm 7.6$ & $51.5 \pm 7.5$ & 0.24 & 0.083 \\
\hline Night time pulse pressure $(\mathrm{mm} \mathrm{Hg})$ & $47.9 \pm 8.3$ & $49.3 \pm 8.3$ & $46.6 \pm 8.4$ & $53.1 \pm 8.3$ & 0.13 & 0.067 \\
\hline
\end{tabular}

Values are arithmetic mean \pm s.d. or geometric mean (5th-95th percentile interval), adjusted for age and body mass index.

Table 4 Independent associations between ambulatory blood pressure and albumin-to-creatinine ratio

\begin{tabular}{|c|c|c|c|c|c|c|}
\hline \multirow[b]{3}{*}{ Dependent variables } & \multicolumn{6}{|c|}{ Albumin-to-creatinine ratio (log $\mathrm{mg} \mathrm{mmol}^{-1}$ ) } \\
\hline & \multicolumn{3}{|c|}{ African men } & \multicolumn{3}{|c|}{ Caucasian men } \\
\hline & $\mathrm{R}^{2}$ & Std $\beta(95 \%$ Cl) & P-value & $\mathrm{R}^{2}$ & Std $\beta(95 \%$ Cl) & $\mathrm{P}$-value \\
\hline \multicolumn{7}{|l|}{ Daytime } \\
\hline Systolic blood pressure (mm Hg) & 0.330 & $0.168(-0.056$ to 0.392$)$ & 0.14 & 0.198 & $0.045(-0.168$ to 0.259$)$ & 0.67 \\
\hline Diastolic blood pressure (mm Hg) & 0.304 & $0.037(-0.191$ to 0.266$)$ & 0.75 & 0.234 & $0.131(-0.077$ to 0.340$)$ & 0.21 \\
\hline Mean arterial pressure $(\mathrm{mm} \mathrm{Hg})$ & 0.328 & $0.096(-0.129$ to 0.320$)$ & 0.40 & 0.239 & $0.107(-0.101$ to 0.315$)$ & 0.31 \\
\hline \multicolumn{7}{|l|}{ Night time } \\
\hline Systolic blood pressure $(\mathrm{mm} \mathrm{Hg})$ & 0.324 & $0.347(0.122$ to 0.572$)$ & 0.003 & 0.203 & $-0.031(-0.244$ to 0.182$)$ & 0.77 \\
\hline Diastolic blood pressure (mm Hg) & 0.328 & $0.298(0.074$ to 0.522$)$ & 0.010 & 0.192 & $-0.042(-0.256$ to 0.173$)$ & 0.70 \\
\hline Mean arterial pressure $(\mathrm{mm} \mathrm{Hg})$ & 0.340 & 0.331 (0.109 to 0.553) & 0.004 & 0.190 & $-0.040(-0.254$ to 0.175$)$ & 0.71 \\
\hline \multicolumn{7}{|l|}{ Arterial stiffness } \\
\hline Pulse wave velocity $\left(\mathrm{m} \mathrm{s}^{-1}\right)^{\mathrm{a}}$ & 0.319 & $0.271(0.025$ to 0.527$)$ & 0.032 & 0.379 & $-0.172(-0.361$ to 0.018$)$ & 0.075 \\
\hline Daytime pulse pressure (mm Hg) & 0.220 & $0.265(0.024$ to 0.507$)$ & 0.032 & 0.109 & $-0.083(-0.308$ to 0.142$)$ & 0.47 \\
\hline Night time pulse pressure $(\mathrm{mm} \mathrm{Hg})$ & 0.208 & $0.258(0.014$ to 0.501$)$ & 0.038 & 0.241 & $-0.00043(-0.208$ to 0.207$)$ & $>0.99$ \\
\hline
\end{tabular}

Abbreviations: $\mathrm{Cl}$, confidence interval; $\operatorname{std} \beta$, standardized $\beta$;

Std $\beta$ reflects the change in the dependent variable for 1 s.d. change in the independent variable. A larger std $\beta$ reflects greater strength of the association. Adjusted for age, body mass index, serum glucose, C-reactive protein, physical activity, current smoking, current drinking and use of antihypertensive medication.

additionally, adjusted for $24 \mathrm{~h}$ mean arterial pressure.

and incident hypertension in non-diabetic, normotensive individuals. ${ }^{20,21}$ Schultz et al. ${ }^{43}$ reported similar results even in children (mean age at follow-up, 15.0 years) with type 1 diabetes mellitus, where blood pressure only rose concurrently with the onset of microalbuminuria. This suggests that urinary albumin excretion could represent additional systemic processes, such as endothelial dysfunction and resultant arterial stiffness that increases blood pressure. Indeed, a growing body of evidence shows that low-grade and clinically diagnosed microalbuminuria is associated with arterial stiffness $^{19,24}$ and peripheral arterial disease. ${ }^{44}$
We believe that the low-grade albumin excretion observed in our study represents, at least in part, general subclinical vascular dysfunction that could contribute to blood pressure elevation, rather than blood pressure causing excessive damage at this stage. There are several reasons for this observation in these relatively young, non-diabetic, HIV-negative Africans: (1) albumin excretion was higher in Africans, independent of blood pressure (Figure 1); (2) kidney function was within normal limits and the associations obtained above were independent of kidney function; and (3) measures of arterial stiffness, that is, daytime pulse pressure, night time pulse pressure and pulse 
wave velocity (together representing systemic elastic and muscular arteries) were positively associated with low-grade albumin excretion. The absence of associations in the Caucasians could quite simply mean healthier arteries in this group as represented by their low mean ACR of $0.22 \mathrm{mg} \mathrm{mmol}^{-1}$.

The mechanism linking albuminuria and arterial stiffness is presently unclear; however, studies propose that vascular endothelial dysfunction may be the underlying mechanism. ${ }^{45,46}$ Indeed, inflammatory stimuli such as histamine, thrombin, vascular endothelial growth factor and activated neutrophils can cause endothelial hyperpermeability and influx of proinflammatory and proatherogenic cellular and non-cellular substances into the vessel wall. ${ }^{47}$ This results in extra-glomerular vascular complications such as atherosclerosis and peripheral vascular disease ${ }^{47}$ At the same time, however, the increased endothelial permeability would also result in albumin leakage at the glomeruli and therefore could represent general vascular dysfunction, explaining the associations between low-grade albuminuria and arterial stiffness.

These findings may have important clinical implications for highrisk groups such as Africans from sub-Saharan Africa, with death occurring frequently from vascular-related events such as stroke, ${ }^{8}$ renal failure ${ }^{9}$ and congestive heart failure. ${ }^{10}$ If low-grade albuminuria could indeed serve as a marker of subtle vascular changes, even in nondiabetic, HIV-negative Africans with normal kidney function, it could be an invaluable biomarker to identify individuals at risk for future cardiovascular events. This could lead to preventative strategies such as more targeted non-pharmacological interventions and follow-up and therefore curb the increasing trend of cardiovascular morbidity and mortality in Africans from sub-Saharan Africa. ${ }^{4,5,48}$

This study must be interpreted within the context of its limitations and strengths. Even though our results were consistent after multiple adjustments, we cannot exclude residual confounding. Also, our sample size was relatively small, especially after excluding participants with microalbuminuria, diabetes or participants infected with HIV. In addition, baseline characteristics were considerably different between African and Caucasian men; therefore, the results may be biased even after adjusting for confounders. However, we believe that this is unlikely due to the consistency of the results after single, partial and multiple regression analyses. We applied a cross-sectional target population design to investigate the associations between arterial stiffness, blood pressure and urinary albumin excretion, and therefore cannot infer causality. Urinary albumin was assessed from an $8 \mathrm{~h}$ overnight urine specimen rather than multiple specimens or a timed collection. However, these collections correlate well with $24 \mathrm{~h}$ collections. ${ }^{31,33}$ We measured the carotid-dorsalis pedis pulse wave velocity, which is a less conventional method. Like the more commonly used brachial-ankle pulse wave velocity, results obtained are from a combination of both elastic and muscular arteries. ${ }^{49}$ However, the pulse wave velocity in this study correlated well with $24 \mathrm{~h}$ systolic $(r=0.32, P<0.01)$ and diastolic blood pressure $(r=0.32, P<0.01)$ and showed a tendency with $24 \mathrm{~h}$ pulse pressure $(r=0.20, P=0.10)$. We used daytime and night time pulse pressure as an indirect measure of aortic stiffness. It is well established that increased aortic stiffness is the predominant cause of increased pulse pressure ${ }^{50}$ and is a marker of cardiovascular risk in the general population. ${ }^{51}$ We conducted a welldesigned study under controlled conditions, and made use of ABPMs. To our knowledge, this is the first study to investigate associations between arterial stiffness, $24 \mathrm{~h}$ ambulatory blood pressure and urinary albumin excretion in African men from sub-Saharan Africa.

In conclusion, low-grade urinary albumin excretion is higher in African men, independent of blood pressure, and is already associated with arterial stiffness and ambulatory blood pressure in non-diabetic, HIV-negative African men with normal kidney function. This supports the hypothesis that low-grade albumin excretion, well below the diagnostic threshold for microalbuminuria $\left(<3.5 \mathrm{mg} \mathrm{mmol}^{-1}\right)$, not only represents glomerular endothelial dysfunction, but also systemic vascular dysfunction. This could possibly serve as an important marker for blood pressure progression and future cardiovascular events, especially in high risk groups such as Africans.

\section{CONFLICT OF INTEREST}

The authors declare no conflict of interest.

\section{ACKNOWLEDGEMENTS}

The Sympathetic Activity and Ambulatory Blood Pressure in Africans (SABPA) study would not have been possible without the voluntary collaboration of the participants and the Department of Education, North West Province, South Africa. We gratefully acknowledge the technical assistance of Mrs Tina Scholtz, Sr Chrissie Lessing and Dr Szabolcs Péter. This work was partially supported by the National Research Foundation, South Africa, North-West University, Potchefstroom, South Africa and the Metabolic Syndrome Institute, France.

1 The World Bank. African Development Indicators 2008/2009: From the World Bank Africa Database. World Bank Publications, Washington, D.C., USA, 2010.

2 Bradshaw D, Schneider M, Dorrington R, Bourne DE, Laubscher R. South African cause-of-death profile in transition-1996 and future trends. S Afr Med J 2002; 92: 618-623.

3 Mayosi BM, Flisher AJ, Lalloo UG, Sitas F, Tollman SM, Bradshaw D. The burden of non-communicable diseases in South Africa. Lancet 2009; 374: 934-947.

4 Bonow RO, Smaha LA, Smith SCJ, Mensah GA, Lenfant C. World Heart Day 2002: the international burden of cardiovascular disease: responding to the emerging global epidemic. Circulation 2002; 106: 1602-1605.

5 Yusuf S, Hawken S, Ounpuu S, Dans T, Avezum A, Lanas F, McQueen M, Budaj A, Pais $\mathrm{P}$, Varigos J, Lisheng L, INTERHEART Study Investigators. Effect of potentially modifiable risk factors associated with miocardial infarction in 52 countries (the INTERHEART study): case-control study. Lancet 2004; 364: 937-952.

6 Opie LH, Seedat YK. Hypertension in sub-Saharan African populations. Circulation 2005; 112: 3562-3568.

7 Thorogood M, Connor M, Tollman S, Hundt GL, Fowkes G, Marsh J. A cross-sectional study of vascular risk factors in a rural South African population: data from the South African Stroke Prevention Initiative (SASPI). BMC Public Health 2007; 7: 326-335.

8 Connor MD, Walker R, Modi G, Warlow CP. Burden of stroke in black populations in subSaharan Africa. Lancet Neurol 2007; 6: 269-278.

9 Plange-Rhule J, Phillips R, Acheampong JW, Saggar-Malik AK, Cappuccio FP, Eastwood JB. Hypertension and renal failure in Kumasi, Ghana. J Hum Hypertens 1999; 13: 37-40.

10 Sliwa K, Wilkinson D, Hansen C, Ntyintyane L, Tibazarwa K, Becker A, Stewart S. Spectrum of heart disease and risk factors in a black urban population in South Africa (the Heart of Soweto Study): a cohort study. Lancet 2008; 371: 915-922.

11 American Diabetes Association. Nephropathy in diabetes (Position Statement). Diabetes Care 2004; 27(Suppl 1): S79-S83.

12 Bigazzi R, Bianchi S, Baldari D, Campese VM. Microalbuminuria predicts cardiovascular events and renal insufficiency in patients with essential hypertension. $J$ Hypertens 1998; 16: 1325-1333.

13 Gerstein HC, Mann JF, Yi Q, Zinman B, Dinneen SF, Hoogwerf B, Halle JP, Young J, Rashkow A, Joyce C, Nawaz S, Yusuf S. Albuminuria and risk of cardiovascular events, death, and heart failure in diabetic and nondiabetic individuals. JAMA 2001; 286: 421-426.

14 Chronic Kidney Disease Prognosis Consortium. Associations of estimated glomerular filtration rate and albuminuria with all-cause and cardiovascular mortality in general population cohorts: a collaborative meta-analysis. Lancet 2010; 375: 2073-2081.

15 Jensen JS, Borch-Johnsen K, Jensen G, Feldt-Rasmussen B. Microalbuminuria reflects a generalized transvascular albumin leakiness in clinically healthy subjects. Clin Sci (Lond) 1995; 88: 629-633.

16 Deckert T, Feldt-Rasmussen B, Borch-Johnsen K, Jensen T, Kofoed-Enevoldsen A. Albuminuria reflects widespread vascular damage: the Steno hypothesis. Diabetologia 1989; 32: 219-226.

17 Wada M, Nagasawa H, Kurita K, Koyama S, Arawaka S, Kawanami T, Tajima K, Daimon $M$, Kato T. Microalbuminuria is a risk factor for serebral small vessel disease in community-based elderly subjects. J Neurol Sci 2007; 255: 27-34.

18 Hoseini VN, Rasouli M. Microalbuminuria correlates with the prevalence and severity of coronary artery disease in non-diabetic patients. Cardiol J 2009; 16: 142-145.

19 Liu C, Pi-Sunyer FX, Li C, Davidson LE, Li T, Chen W, Lin C, Huang C, Lin W. Albuminuria is strongly associated with arterial stiffness, especially in diabetic or 
hypertensive subjects - a population-based study (Taichung Community Health Study, TCHS). Atherosclerosis 2010; 211: 315-321.

20 Gerber LM, Schwartz JE, Pickering TG. Albumin-to-creatinine ratio predicts change in ambulatory blood pressure in normotensive persons: a 7.5-year prospective study. Am J Hypertens 2006; 19: 220-226.

21 Wang TJ, Evans JC, Meigs JB, Rifai N, Fox CS, D'Agostino RB, Levy D, Vasan RS. Low-grade albuminuria and the risks of hypertension and blood pressure progression. Hypertension 2005; 111: 1370-1376.

22 Clausen P, Jensen JS, Jensen G, Borch-Johnsen K, Feldt-Rasmussen B. Elevated urinary albumin excretion is associated with impaired arterial dilatory capacity in clinically healthy subjects. Circulation 2001; 103: 1869-1874.

23 Clausen P, Feldt-Rasmussen B, Jensen G, Jensen JS. Endothelial haemostatic factors are associated with progression of urinary albumin excretion in clinically healthy subjects: a 4-year prospective study. Clin Sci (Lond) 1999; 97: 37-43.

24 Hermans MMH, Henry R, Dekker JM, Kooman JP, Kostense PJ, Nijpels G, Heine RJ, Stehouwer CDA. Estimated glomerular filtration rate and urinary albumin excretion are independently associated with greater arterial stiffness: the Hoorn study. J Am Soc Nephrol 2007; 18: 1942-1952.

25 Ärnlöv J, Evans JC, Meigs JB, Wang TJ, Fox CS, Levy D, Benjamin EJ, D’Agostino RB, Vasan RS. Low-grade albuminuria and incidence of cardiovascular disease events in nonhypertensive and nondiabetic individuals: the Framingham study. Circulation 2005; 112: 969-975.

26 American Diabetes Association. Diagnosis and classification of diabetes mellitus. Diabetes Care 2005; 28(Suppl 1): S37-S42.

27 Mancia G, De BG, Dominiczak A, Cifkova R, Fagard R, Germano G, Grassi G, Heagerty AM, Kjeldsen SE, Laurent S, Narkiewicz K, Ruilope L, Rynkiewicz A, Schmieder RE, Boudier HA, Zanchetti A. 2007 Guidelines for the management of arterial hypertension. J Hypertens 2007; 25: 1105-1187.

28 van Bortel LMAB, Struijker-Boudier HAJ, Safar ME. Pulse pressure, arterial stiffness, and drug treatment of hypertension. Hypertension 2001; 38: 914-921.

29 Marfell-Jones M, Olds T, Stewart A, Zarter L. International Standards for Anthropometric Assessment. ISAK, Potchefstroom, South Africa, 2006.

30 Klippel NJ, Heil DP. Validation of energy expenditure prediction algorithms in adults using the Actical electronic activity monitor. Med Sci Sports Excerc 2003; 35: S284.

31 Bakker AJ. Detection of microalbuminuria: receiver operating characteristic curve analysis favors albumin-to-creatinine ratio over albumin concentration. Diabetes Care 1999; 22: 307-313.

32 Dyer AR, Greenland P, Elliot P, Daviglus ML, Claeys G, Kesteloot H, Chan Q, Ueshima $\mathrm{H}$, Stamler J. Estimating laboratory precision of urinary albumin excretion and other urinary measures in the International Study on Macronutrients and Blood Pressure. Am J Epidemiol 2004; 160: 287-294.

33 Nathan DM, Rosenbaum C, Protasowicki VD. Single-void urine samples can be used to estimate quantitative microalbuminuria. Diabetes Care 1987; 10: 414-418.

34 Cockcroft DW, Gault MH. Prediction of creatinine clearance from serum creatinine. Nephron 1976; 16: 31-41.
35 Jensen JS, Feldt-Rasmussen B, Strandgaardt S, Schroll M, Borch-Johnsen K. Arterial hypertension, microalbuminuria, and risk of ischemic heart disease. Hypertension 2000; 35: 898-903.

36 Dinneen SF, Gerstein HC. The association of microalbuminuria and mortality in noninsulin-dependent diabetes mellitus: a systemic overview of the literature. Arch Intern Med 1997; 157: 1413-1418.

37 Knight EL, Kramer HM, Curhan GC. High-normal blood pressure and microalbuminuria. Am J Kidney Dis 2003; 41: 588-595.

38 Brenner BM, Garcia DL, Anderson S. Glomeruli and blood pressure: less of one, more the other? Am J Hypertens 1988; 1: 335-347.

39 Burnier M. Ethnic differences in renal handling of water and solutes in hypertension. Hypertension 2008; 52: 203-204.

40 Morgensen CE. Microalbuminuria predicts clinical proteinuria and early mortality in maturity-onset diabetes. N Engl J Med 1984; 310: 356-360.

41 Burnier M, Coltamai L, Maillard M, Bochud M. Renal sodium handling and nighttime blood pressure. Semin Nephrol 2007; 27: 565-571.

42 Ingelfinger JR. Is microanatomy destiny? N Engl J Med 2003; 348: 99-100.

43 Schultz CJ, Neil HAW, Dalton RN, Bahu TK, Dunger DB, Oxford Regional Prospective Study Group. Blood pressure does not rise before the onset of microalbuminuria in children followed from diagnosis of type 1 diabetes. Diabetes Care 2001; 24: 555-560.

44 Choi SW, Yun WJ, Kim HY, Lee YH, Kweon SS, Rhee JA, Choi JS, Shin MH. Association between albuminuria, carotid atherosclerosis, arterial stiffness, and peripheral arterial disease in Korean type 2 diabetic patients. Kidney Blood Press Res 2010; 33: $111-118$

45 Asselbergs FW, de Boer RA, Diercks GFH, Langeveld B, Tio RA, de Jong PE, van Veldhuisen DJ, van Gilst WH. Vascular endothelial growth factor: the link between cardiovascular risk factors and microalbuminuria? Int J Cardiol 2004; 93: 211-215.

46 Hillege HL, Janssen WH, Bak AA, Diercks GF, Grobbee GE, Crijns HJ, van Gilst WH, De Zeeuw D, de Jong PE, Prevend Study Group. Microalbuminuria is common, also in a nondiabetic, nonhypertensive population, and an independent indicator of cardiovasular risk factors and cardiovascular morbidity. J Intern Med 2001; 249: 519-526.

47 Kumar P, Shen Q, Pivetti CD, Lee ES, Wu MH, Yuan SY. Molecular mechanisms of endothelial hyperpermeability: implications in inflammation. Expert Rev Mol Med 2009; 11: e19.

48 Murry CJ, Lopez AD. Alternative projections of mortality and disability by cause 19902020: global burden of disease study. Lancet 1997; 349: 1498-1504.

49 Cameron JD, Pinto ES, Bulpitt CJ, Rajkumar C. The aging of elastic and muscular arteries: a comparison of diabetic and nondiabetic subjects. Diabetes Care 2003; 26: 2133-2138.

50 Dart AM, Kingwell BA. Pulse pressure: a review of mechanisms and clinical relevance. J Am Coll Cardiol 2001; 37: 975-984.

51 Benetos A, Safar M, Rudnichi A, Smulyan H, Richard J-L, Cucimetiere P, Guize L. Pulse pressure a predictor of long-term cardiovascular mortality in a French male population. Hypertension 1997; 30: 1410-1415. 